\title{
Sustainable Food Supply Chains: Towards a Framework for Waste Identification
}

\author{
Lukas Chabada $^{1}$, Heidi Carin Dreyer ${ }^{1}$, Anita Romsdal ${ }^{2}$, and Daryl John Powell ${ }^{1}$ \\ ${ }^{1}$ Department of Production and Quality Engineering, \\ Norwegian University of Science and Technology (NTNU), Trondheim, Norway \\ \{lukas.chabada, heidi.c.dreyer, daryl.j.powell\}@ntnu.no \\ ${ }^{2}$ SINTEF Technology and Society, Trondheim, Norway \\ anita.romsdalesintef.no
}

\begin{abstract}
Reduction of waste in food supply chains is an important sustainability issue. More efficient utilisation and management of the resources and values created in food supply chains can contribute to improving competitiveness, and environmental and social responsibility. This study uses the seven wastes approach from lean theory to classify categories of waste in fresh food supply chains and to identify at which stage of the supply chain waste occur. A case is used to illustrate the applicability of the classification. The analysis identifies four categories of waste in the fresh food supply chain; time, distance, energy and mass. The study indicates that the majority of waste is hidden in time, energy and mass categories, related to overproduction, defects and transportation.
\end{abstract}

Keywords: fresh food, waste, lean, food supply chain.

\section{Introduction}

The food sector, represented by farmers, food producers, wholesalers and retailers, creates and manages enormous values and resources. Achieving a sustainable production, distribution and consumption of these values is a significant global responsibility since it affects social development, welfare and health, economic development and competitiveness for actors in the food supply chain, and environmental conditions. The expected population explosion puts direct pressure on global food production (Parfitt et al., 2010, Godfray et al., 2010) and stresses the need for addressing sustainability issues related to the level of waste stemming from resource inefficiencies in food supply chains (Mena et al., 2011).

Cultivating, processing and distributing food which ends up as waste leads to a major loss in value creation (Akkerman et al., 2010). Almost one-third of food produced for human consumption is lost or wasted globally and the level is significantly increasing (Gustavsson et al., 2011). One example of food products being wasted are fresh food products with very short shelf life which need to be processed quickly. A critical question from a logistical point of view is what type of waste are we dealing with and where in the supply chain, and how can new ways to 
control and operate the supply chain contribute to lower the amount of waste. What we know is that a good balance between supply and demand of products in the supply chain will reduce the level of products that will never be sold. We also know that the different stages in the supply chain needs to be integrated, the lead time needs to be kept short, and the inventory level low in order to reduce the risk of creating waste.

There is growing interest in research on waste in food supply chains. Previous studies have concluded that food waste can be found at every stage of the food supply chain (see e.g. Gustavsson et al., 2011). However, lack of studies on systematic and formal definitions and classifications which can assist in defining waste has been identified in research on waste resulting from unnecessary production and distribution activities for high perishable products (Rajurkar and Jain, 2011). This study uses the seven wastes approach from lean which has proved to be very useful for identifying waste in manufacturing processes (Ohno, 1988). The purpose of this paper is therefore to use the seven wastes perspective from lean in order to develop a classification for identifying waste in fresh food supply chains. The classification addresses two research questions (RQ): What types of waste can be identified in food supply chains (RQ1)? And where in the food supply chain can these wastes be found (RQ2)?

The paper further describes the research methodology and then briefly characterises fresh food supply chains. Next, the seven wastes perspective is used to develop the classification and a case is used to illustrate the applicability of the classification.

\section{Research Methodology}

This research is part of a project focused on sustainable logistics in Nordic fresh food supply chains. The study is carried out by researchers within supply chain management focusing on different aspects of coordination, collaboration, planning and control, and real-time information. The objective of the paper is to develop a classification for waste identification in fresh food supply chains, with focus on producers, wholesalers and retailers. The classification is based on a study of food supply chain and lean theory literature, with particular focus on waste. In order to demonstrate the applicability and relevance of the classification, a Norwegian salad producer is used as an illustrative case. The case was selected due to the fact that the company addresses waste prevention and sustainability as a strategic priority. Data were collected in interviews, discussions and observations during company visits. Interviews and discussions have been conducted in physical meetings and workshops between company representatives and researchers.

\section{Fresh Food Supply Chain Characteristics}

From a supply chain and logistics perspective, there is number of characteristics particular to fresh food supply chains, see Table 1. In general, market and product characteristics tend to push for shorter lead times and higher responsiveness, while the 
production system with its focus on economies of scale tends to increase lead times (Romsdal et al., 2011). Thus, the way the supply chain and its processes are designed and planned can often result in mismatch of demand and supply, creating high stock levels, increasing the time spent on non-value added operations or contributing to overproduction and increased defects rate.

Table 1. Fresh food supply chain characteristics (based on Romsdal et al., 2011)

\begin{tabular}{ll}
\hline Area & Characteristics \\
\hline Product & - High perishability (raw materials, intermediate and finished products) \\
& - Increasing product variety, packaging sizes and receipts \\
Market & - Customers demand frequent deliveries and short response times \\
& - Varying and increasing demand uncertainty \\
& - Limited ability to keep stock \\
& - Cost of lost sales often higher than inventory carrying costs \\
Production & - Long production lead times, long set-up times, high set-up costs \\
system & - Production adapted to high volume, low variety \\
\hline
\end{tabular}

Previous studies have identified food waste in all stages of the food supply chain and classified it mostly based on different food product types or production, processing and transportation processes (Parfitt et al., 2010, Gustavsson et al., 2011, Mena et al., 2011). Darlington et al. (2009) pointed out also other wastes in the food supply chain, including bulk waste, water waste, processing waste, packaging waste and overproduction waste. Dudbridge (2011) discusses six out of the seven wastes of lean theory and uses his experience from the food industry to discuss food and other wastes in the food supply chain. His contribution is, however, missing more consistency structure and connection to academic relevance. The discussion above, therefore, shows the lack of attention that has been given to consistent mapping and classifying of different wastes occurring in fresh food supply chains operations.

\section{Identification of Waste in Fresh Food Supply Chains}

The purpose of this paper is to address the gap mentioned above by using the seven wastes from lean as a basis for constructing a classification for waste identification in fresh food supply chains. The study focuses on food producers, wholesalers and retailers in the supply chain. Next, the seven wastes are explained and related to different activities in fresh food supply chains and four wasted categories are identified.

\subsection{Seven Wastes of Lean and Fresh Food Supply Chains}

The systematic identification and elimination of waste is known to be a central element of the Lean Production philosophy (Ohno, 1988, Liker, 2004, Shingo and Dillon, 1989). In order to identify waste in manufacturing processes, Ohno (1988) classifies seven types of waste: Transportation, Inventory, Motion, Waiting, Overproduction, Over-processing, and Defects. Though these seven types of waste 
have proven to be very useful for identifying waste in the production of discrete automotive components, this type of classification fails to illustrate much of the waste inherent to fresh food supply chains.

Lean theory defines waste as any activity that adds cost or consumes time but does not add value to the customer (Womack and Jones, 2005, Ohno, 1988). Value added activities describe the best combination of processes and operations which are necessary to make the product, delivering the highest quality, for the lowest cost, on time to the customer (Ohno, 1988). In order to find out how much is spent on both value added and non-value added activities, lean theory offers different tools, such as Value Stream Mapping. However, this technique places emphasis on time as a main resource which is wasted. This, however, does not precisely shows all the wastes created in the fresh food supply chain, not including wasted food or energy. Therefore, other categories are added in the proposed waste classification. The categories were chosen on a basis of findings from literature studying operation management considering fresh food characteristics. First category is time which materials, products, equipment, machines and people spend in specific process or operation (Jones and Womack, 2002, Dudbridge, 2011). Second is distance showing how many meters or kilometres were spent on transportation of materials and products (McCarthy and Rich, 2004, Dudbridge, 2011). Third one is energy represented by electricity and fuel spent by tracks, conveyors, fridges, freezers and other equipment and machines (Dudbridge, 2011, Swink et al., 2011). Last suggested category is mass, representing the amount of materials and products which are processed and distributed across the supply chain (Gustavsson et al., 2011, Parfitt et al., 2010).

\subsection{Towards a Framework for Waste Identification}

Below, each of the seven wastes are discussed in terms of the four categories of waste and related to the three actors of the food supply chain; food producers, wholesalers and retailers (based on Ohno, 1988, Jones and Womack, 2002, Dudbridge, 2011).

Transportation as itself is a value-added activity bringing the product closer to the customer. Transportation waste is then an unnecessary transportation of materials and products within or outside the company tiding extra time, distance and energy, and by excessive handling of sensitive fresh food products contributing to food waste (Hines and Taylor, 2000). For instance, moving material from and to the distant machine at food producer, transporting materials and products from one place to another just to make a place for new inventory at wholesaler, or moving the products from the store inventory to the shelf and back at retailer stage (Hallihan et al., 1997).

A certain amount of inventory is necessary in order to be responsive in fulfilling uncertain customer demand, keeping customer service level high. Inventory waste is therefore characterized as unnecessary inventory in a form of raw materials, work-inprocess, or finished goods that exceed what is required to meet customer needs just in time and to meet needs of the process being smoothly performed (Sutherland and Bennett, 2007). This ties extra valuable time from shelf life, energy of cooling equipment and often leads to food waste. Examples of inventory waste might be all products that are not sold due the deadline determined by safety regulations, or due to product deterioration at every stage of the food supply chain. 
Motion waste can be defined as time spent on unnecessary movements of operator such as unnecessary walking, stretching or reaching for a tool or equipment (Sutherland and Bennett, 2007). Examples are movement of operator to pick the packing tape, reaching for the hammer or walking distance to the pallet while filling the shelf in the store. Motion waste could be reduced by better ergonomics.

Waiting waste is an unnecessary waiting of the machines and people spending extra time of labour and energy of idling machines (Sutherland and Bennett, 2007). It might be seen as time operator is waiting to assemble next product or packing machine waiting for products to be delivered or operator waiting for products which should be loaded into a shelf of retail store.

Overproduction means making what is unnecessary, when it is unnecessary, and in unnecessary amounts. It occurs when items for which there are no orders are produced. Overproduction in its original sense occurs only at the food producer level when too many products are produced even there is no order for them. On the wholesaler and retailer level, overproduction can be seen as ordering more than is demanded to buffer against uncertainties in demand timing and quantities. Overproduction increases inventory and spends extra time, distance, energy and mass.

Over-processing waste refers to any processes that do not add value to the customer or give more value to the product that is agreed standard. This takes extra time and energy and increases risk of products being wasted. Examples of this waste are excessive quality check of fresh products at every stage of the supply chain.

Defects include wasted materials and products during the production and distribution process, and rejected materials and products which have to be reworked (Dudbridge, 2011, Sutherland and Bennett, 2007, McCarthy and Rich, 2004). Waste from rework includes resources needed to make repairs, while waste from rejects results in waste of time, energy, and all other resources put into food products during their production and distribution. The cost of inspecting for defects and responding to customer complaints is also waste related to defects.

Table 2 summarises the discussion above in terms of time, distance, energy and mass, and shows at which stages in the food supply chain they can be identified. The classification shows that time, energy and mass are the most common wastes across the food supply chain and the main contributors are overproduction, defects and transportation followed by inventory waste. On the other hand, the least waste seems to be related to excessive motion.

Table 2. Classification of wastes in fresh food supply chains

\begin{tabular}{lcccccccccccc}
\hline Actors in the FSC & \multicolumn{4}{c}{ Food producers } & \multicolumn{3}{c}{ Wholesalers } & \multicolumn{4}{c}{ Retailers } \\
The 7 wastes / Categories & Time & Dist. & Ener. & Mass & Time & Dist. & Ener. Mass & Time & Dist. & Ener. & Mass \\
\hline Transportation & $\mathrm{X}$ & $\mathrm{X}$ & $\mathrm{X}$ & $\mathrm{X}$ & $\mathrm{X}$ & $\mathrm{X}$ & $\mathrm{X}$ & $\mathrm{X}$ & $\mathrm{X}$ & $\mathrm{X}$ & $\mathrm{X}$ & $\mathrm{X}$ \\
Inventory & $\mathrm{X}$ & & $\mathrm{X}$ & $\mathrm{X}$ & $\mathrm{X}$ & & $\mathrm{X}$ & $\mathrm{X}$ & $\mathrm{X}$ & & $\mathrm{X}$ & $\mathrm{X}$ \\
Motion & $\mathrm{X}$ & & & & $\mathrm{X}$ & & & $\mathrm{X}$ & & \\
Waiting & $\mathrm{X}$ & & $\mathrm{X}$ & & $\mathrm{X}$ & $\mathrm{X}$ & & $\mathrm{X}$ & $\mathrm{X}$ & \\
Overproduction & $\mathrm{X}$ & $\mathrm{X}$ & $\mathrm{X}$ & $\mathrm{X}$ & $\mathrm{X}$ & $\mathrm{X}$ & $\mathrm{X}$ & $\mathrm{X}$ & $\mathrm{X}$ & $\mathrm{X}$ & $\mathrm{X}$ & $\mathrm{X}$ \\
Over-processing & $\mathrm{X}$ & & $\mathrm{X}$ & & $\mathrm{X}$ & $\mathrm{X}$ & & $\mathrm{X}$ & & $\mathrm{X}$ & \\
Defects & $\mathrm{X}$ & $\mathrm{X}$ & $\mathrm{X}$ & $\mathrm{X}$ & $\mathrm{X}$ & $\mathrm{X}$ & $\mathrm{X}$ & $\mathrm{X}$ & $\mathrm{X}$ & $\mathrm{X}$ & $\mathrm{X}$ & $\mathrm{X}$ \\
\hline
\end{tabular}




\section{Case: The Salad Supply Chain}

In order to illustrate how the waste classification can be used, a case from the Norwegian food sector is used. The case consists of a supply chain for distribution of processed salads from producer, through a distribution point to a typical grocery store (Yggeseth, 2008, Strandhagen et al., 2011). The shelf life of the salad is around 8-10 days from the production date. The supply chain is illustrated in Fig. 1, showing actors, material and information flow, stock points and physical process.

The factory produces several variants of salads and the production process for most products consists of quality inspections, cutting, washing, and assembly into various product mixes, before packing and storing. Salads are manufactured to stock, but orders from distributors or wholesalers are used for estimating procurement, production, and supply planning. Production planning uses principle of optimal batchsizing.

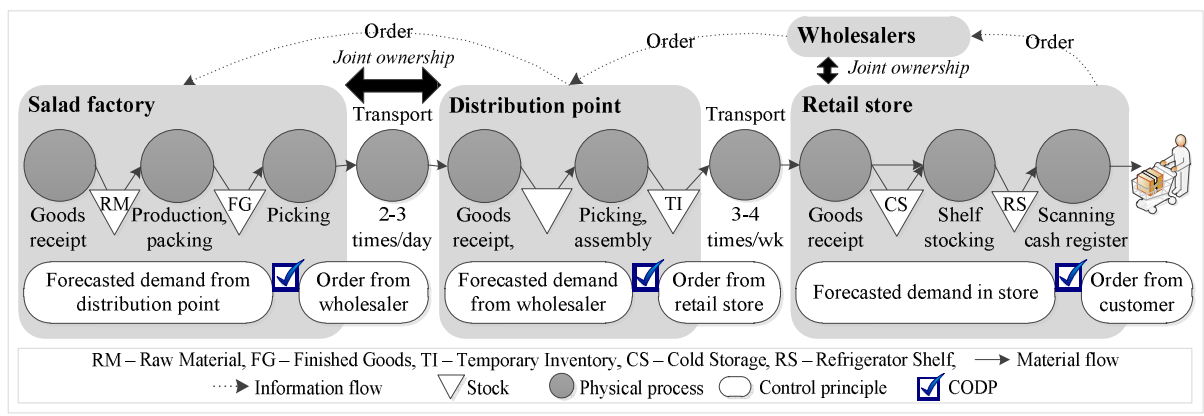

Fig. 1. The salad supply chain

Products are kept in stock at the factory until orders arrive. Salads are distributed directly to restaurants and larger institutions and through wholesalers or distribution points to retail stores. From the factory, products are shipped to a distribution point where retailer orders are assembled. The distribution point is merely a cross-docking facility, and within an $8-10$ hour timeframe the products are transported to retail stores. Accumulated orders are received from a central information system operated by the retail chain's wholesale unit. Throughout the supply chain, products are kept within a strictly regulated temperature zone.

\section{Discussion and Conclusion}

The waste classification from Table 2 can be used as follows. First, on the basis of the seven wastes definitions and proposed wasted categories we try to identify these in the operations of the supply chain. Transportation waste could be spotted as unnecessary transport of products between several stock and distribution points. Deeper investigation could show how many man-hours, and how much fuel and 
electricity is spent unnecessarily. Inventory waste can be counted as the amount of products wasted in the multiple stock points and buffers along the supply chain as products waiting for orders to arrive. Overproduction waste can be indicated from planning based on forecasting and production planning based on optimal batch-sizes. Over-processing waste could be multiple quality checks of salads at four stages in the supply chain (salad factory, distribution point, wholesaler, and retail store). Finally, defects waste can be spotted during an excessive handling of temperature sensitive products resulting in waste. Identification of motion and waiting waste in this case would require deeper analysis of the shop floor activities.

From the above, we see that the classification assisted in identifying a number of wastes beyond the simple perspective of volumes of food being wasted or thrown away in the supply chain. We observe that several of the wastes stem from the way the supply chain is designed and managed. For instance, the lack of sharing of real demand data with upstream actors can lead to excessive use of resources put into producing, moving and storing products with no actual order. The multiple stock and handling points along the supply chain also increase lead time, energy and food waste.

This paper has added to the literature on waste in fresh food supply chains by identifying the types of wastes (RQ1) and where these can be found in food supply chains (RQ2) (see Table 2). Different categories of waste (time, distance, energy and mass) have been identified and discussed within each of the seven wastes and for the different supply chain actors. The applicability of the classification has been illustrated in a case. A theoretical contribution is an increased understanding of waste in fresh food supply chains. By applying the seven wastes perspective from lean, the paper contributes with new insights into how waste can be identified not only in production but also in the wholesale and retail operations. In practice, the classification can assist supply chain actors in analysing their processes and thus provide a basis for identifying the causes of to reduce waste. A limitation of the study lies in its limited focus on three supply chain actors and in its limited focus on physical flow only, excluding information flow analysis. The classification suggest the same types of wastes for each actor of the supply chain, However, the priority to reduce these wastes might be different for each of the actors. Further research should therefore focus on conducting more empirical cases which would verify and complement the findings of the waste classification Also, the trade-offs between different measures must be evaluated, where for instance less inventory could result in increased transportation waste.

Acknowledgement. This study has been made possible by the funding received from Nordic research organization NordForsk via LogiNord project.

\section{References}

1. Akkerman, R., Farahani, P., Grunow, M.: Quality, safety and sustainability in food distribution: a review of quantitative operations management approaches and challenges. OR Spectrum 32, 863-904 (2010)

2. Darlington, R., Staikos, T., Rahimifard, S.: Analytical methods for waste minimisation in the convenience food industry. Waste Management 29, 1274-1281 (2009) 
3. Dudbridge, M.: Handbook of Lean Manufacturing in the Food Industry. Wiley Online Library (2011)

4. Godfray, H.C.J., Beddington, J.R., Crute, I.R., Haddad, L., Lawrence, D., Muir, J.F., Pretty, J., Robinson, S., Thomas, S.M., Toulmin, C.: Food security: the challenge of feeding 9 billion people. Science 327, 812-818 (2010)

5. Gustavsson, J., Cederberg, C., Sonesson, U., van Otterdijk, R., Meybeck, A.: Global food losses and food waste. Food and Agriculture Organization of the United Nations, Rome (2011)

6. Hallihan, A., Sackett, P., Williams, G.: JIT manufacturing: the evolution to an implementation model founded in current practice. International Journal of Production Research 35, 901-920 (1997)

7. Hines, P., Taylor, D.: Going lean. Lean Enterprise Research Centre Cardiff Business School, Cardiff (2000)

8. Jones, D., Womack, J.: Seeing the whole. Lean Enterprise Institute, Brookline (2002)

9. Liker, J.K.: The Toyota way: 14 management principles from the world's greatest manufacturer. McGraw-Hill, New York (2004)

10. McCarthy, D., Rich, N.: Lean TPM: a blueprint for change. Butterworth-Heinemann (2004)

11. Mena, C., Adenso-Diaz, B., Yurt, O.: The causes of food waste in the supplier-retailer interface: Evidences from the UK and Spain. Resources, Conservation and Recycling 55, 648-658 (2011)

12. Ohno, T.: Toyota Production System: Beyond large-scale production. Productivity Press, New York (1988)

13. Parfitt, J., Barthel, M., Macnaughton, S.: Food waste within food supply chains: quantification and potential for change to 2050. Philosophical Transactions of the Royal Society of London. Series B, Biological Sciences 365, 3065-3081 (2010)

14. Rajurkar, S.W., Jain, R.: Food supply chain management: review, classification and analysis of literature. International Journal of Integrated Supply Management 6, 33-72 (2011)

15. Romsdal, A., Thomassen, M., Dreyer, H.C., Strandhagen, J.O.: Fresh food supply chains; characteristics and supply chain requirements. In: 18th International Annual EurOMA Conference. Cambridge University, Cambridge (2011)

16. Shingo, S., Dillon, A.P.: A study of the Toyota production system from an industrial engineering viewpoint. Productivity Press, New York (1989)

17. Strandhagen, J.O., Dreyer, H.C., Romsdal, A.: Control Model for Intelligent and DemandDriven Supply Chain. In: Flynn, B., Morita, M., Machuca, J. (eds.) Managing Global Supply Chain Relationships. Business Science Reference (an imprint of IGI Global), Hersey (2011)

18. Sutherland, J., Bennett, B.: The seven deadly wastes of logistics: applying Toyota Production System principles to create logistics value. White Paper (2007)

19. Swink, M., Melnyk, S., Cooper, M.B., Hartley, J.L.: Managing operations across the supply chain. McGraw-Hill, Irwin (2011)

20. Womack, J.P., Jones, D.T.: Lean solutions: how companies and customers can create value and wealth together. Free Pr. (2005)

21. Yggeseth, F.: Ferskere produkter og mer effektiv logistikk i dagligvarebransjen. Master Thesis, Norwegian University of Science and Technology (2008) 